\title{
Avaliação da divergência nutricional de genótipos de cana-de-açúcar (Saccharum spp. $)^{1}$
}

\author{
Acyr Wanderley de Paula Freitas ${ }^{2}$, José Carlos Pereira ${ }^{3}$, Fernanda Cipriano Rocha ${ }^{4}$, Edenio \\ Detmann $^{3}$, Márcio Henrique Pereira Barbosa ${ }^{5}$, Marinaldo Divino Ribeiro ${ }^{6}$, Marcone Geraldo Costa ${ }^{6}$ \\ ${ }^{1}$ Parte da tese de Doutorado em Zootecnia do primeiro autor. \\ 2 Instituto de Zootecnia. \\ ${ }^{3}$ Departamento de Zootecnia-UFV. \\ ${ }^{4}$ Doutora em Zootecnia - UFV. \\ ${ }^{5}$ Departamento de Fitotecnia - UFV. \\ ${ }^{6}$ Pós-Graduação em Zootecnia - UFV.
}

RESUMO - Objetivou-se neste trabalho avaliar a divergência nutricional de genótipos de cana-de-açúcar para uso na alimentação de animais ruminantes. Foram avaliados os genótipos: RB72454, RB835486, SP80-1842, IAC86-2480, RB977512, RB867515, RB935566, RB925345, RB977625, SP79-1011, SP80-1816, SP81-3250 e SP91-1049, colhidos em soca aos 11 meses de idade, quanto às variáveis FDN, hemicelulose, lignina, relação FDN x carboidratos solúveis, fração indegradável da FDN, taxa de degradação da FDN e taxa de degradação da matéria seca. A aplicação da análise de agrupamento segundo o método de Tocher, utilizando a matriz de distâncias euclidiana média, permitiu o estabelecimento de três grupos de genótipos. A FDN e a taxa de degradação da MS foram as variáveis de maior importância para a discriminação dos grupos, contribuindo cada uma com $25,64 \%$ do poder de discriminação total. A fração indegradável da FDN foi a variável que apresentou a menor contribuição para discriminação dos grupos (11,54\%). A variáveis FDN, fração indegradável da FDN, hemicelulose, taxa de degradação da MS e taxa de degradação da FDN mostraram-se eficazes para o estudo da diversidade nutricional da canade-açúcar. O grupo III, constituído pelo clone RB977512, apresentou as melhores médias para as variáveis avaliadas e, portanto, pode ser considerado de melhor qualidade nutricional para alimentação de ruminantes.

Palavras-chave: análise de agrupamento, degradação ruminal, fibra

\section{Evaluation of the nutritional divergence of sugarcane (Saccharum spp.) genotypes}

\begin{abstract}
The objective of this trial was to study the nutritional divergence of sugarcane genotypes for feeding ruminants. The following sugarcane genotypes were evaluated: RB72454, RB835486, SP80-1842, IAC86-2480, RB977512, RB867515, RB935566, RB925345, RB977625, SP79-1011, SP80-1816, SP81-3250, and SP91-1049 all harvested at 11 months of age. The discriminatory variables were: neutral detergent fiber (NDF), hemicellulose, lignin, NDF to soluble carbohydrate ratio, NDF undegradable fraction, and rates of NDF and DM degradation. Application of the cluster analyses according to the Tocher approach, using the mean Euclidian distance matrix, yielded three groups of genotypes. Neutral detergent fiber and DM degradation rates were the most important variables for group discrimination contributing individually with $25.64 \%$ of the total discrimination power while the least contribution was observed with NDF undegradable fraction (11.54\%). The variables NDF, NDF undegradable fraction, hemicellulose, and rates of DM and NDF degradation all showed to be effective to evaluate sugarcane nutritional divergence. Group III formed by the clone RB977512 showed the best responses for the studied variables and as such can be considered of higher nutritional quality for ruminants.
\end{abstract}

Key Words: cluster analyses, fiber, ruminal degradation

\section{Introdução}

A cana-de-açúcar (Saccharum spp.) tem sido intensamente utilizada na alimentação de bovinos. A facilidade de cultivo, a possibilidade de colheita justamente nos períodos de estiagem e a alta produtividade em condições tropicais tornam essa forrageira de grande interesse nos sistemas de produção de bovinos.

O Brasil é atualmente o maior produtor de cana-deaçúcar do mundo, com área cultivada de aproximadamente,
5,5 milhões de hectares, estimando-se que 10\% desta área seja destinada à alimentação animal, sendo produzidos em torno de 30 milhões de toneladas de massa verde (Landell et al., 2002).

Atualmente, o plantio da cana-de-açúcar se baseia quase que exclusivamente na utilização de híbridos (clones) complexos das espécies do gênero Saccharum, o que permite redução do custo de produção da cana-de-açúcar e aumento nos ganhos em produtividade. Quando se observa 
a evolução da produtividade da cultura nos estados de Minas Gerais e de São Paulo, desde a década de 70, verificam-se, respectivamente, ganhos anuais de 0,83 e 1,41 toneladas de cana por hectare e 1,37 e $0,89 \mathrm{~kg}$ de açúcar por tonelada de cana (Barbosa, 2000).

Diferenças na qualidade entre espécies e variedades de gramíneas são bastante conhecidas (Collins \& Casler, 1990a; 1990b) e, portanto, o melhoramento genético da planta forrageira pode influenciar a qualidade da forragem. Anderson et al. (1988) desenvolveram um cultivar de Panicum virgatum com maior digestibilidade in vitro da matéria seca e observaram maiores ganhos por animal com o cultivar melhorado em relação à linhagem não-selecionada. Hall et al. (1994) modificaram a taxa de degradação in vitro da alfafa para diminuir o potencial desta forragem em provocar timpanismo. Existem vários outros exemplos da utilização do melhoramento genético como recurso para aprimorar a qualidade de plantas forrageiras.

Há muito se preconiza que a melhor variedade para a indústria de açúcar é também a melhor para ser utilizada como forrageira, pois apresenta melhor teor de açúcar, interessante para alimentação animal. No entanto, a canade-açúcar envolve numerosas variedades com características bastante diversificadas e, especificamente quando se destina à alimentação animal, as principais características são a produção de matéria seca (cana planta e soca), a facilidade de colheita e a qualidade nutritiva, observando-se não somente seu teor de açúcar, como também a qualidade da fibra.

Entretanto, uma das limitações quanto ao uso da canade-açúcar na alimentação animal é o seu baixo teor de proteína, aliado à baixa digestibilidade da fibra. Na seleção de variedades para a indústria, pouca atenção é dada à qualidade da fibra da planta, o que pode afetar de maneira adversa o seu valor nutritivo para bovinos.

O termo qualidade refere-se à totalidade de fatores que influenciam o valor nutritivo das plantas forrageiras para os animais, de modo que os principais fatores estão relacionados à qualidade da forragem e à digestibilidade e ao consumo de alimentos, que, em última instância, determinam o suprimento de nutrientes para os diferentes processos fisiológicos (Van Soest, 1991).

O baixo consumo voluntário da cana-de-açúcar está associado à baixa degradação de sua fibra no rúmen, o que provoca acúmulo de fibra não-degradada, limitando o consumo por repleção ruminal. Dietz et al. (1997) observaram que a degradabilidade da fibra em detergente neutro(FDN) da cana-de-açúcar no rúmen de bovinos iniciou-se somente após 24 horas de incubação in situ.
De acordo com Poppi et al. (1985), a ingesta sofre maior resistência para sair do rúmen até ser reduzida a tamanhos de partículas pequenos $(\leq 1,18 \mathrm{~mm})$. Se este processo é rápido, o alimento degradado pode ser substituído por mais alimento consumido. Se a degradação é prolongada, o enchimento ruminal irá limitar o consumo. É interessante, então, a seleção de variedades com taxas de degradação mais elevadas, o que pode favorecer o consumo de alimento.

Segundo Gooding (1982), um parâmetro importante na escolha de variedades de cana-de-açúcar para ruminantes é a relação entre o conteúdo de FDN e o teor de açúcares, de modo que, quanto menor esta relação, melhor a variedade para uso como forrageira. De acordo com Rodrigues et al. (2001), deve-se selecionar variedades com menor relação FDN/açúcares para alimentação de bovinos a fim de se evitar que o maior teor de FDN de algumas variedades limite o consumo pelo animal e, conseqüentemente, o consumo de açúcares, componente que fornece a maior parte da energia digestível da cana.

Rodrigues et al. (2002), ao avaliarem o valor nutritivo de variedades de cana-de-açúcar para novilhas com peso médio inicial de 219,1 kg e 12,3 meses de idade, verificaram médias diárias de ganho de peso vivo de 0,65 a $0,89 \mathrm{~kg} /$ animal e conversão alimentar de 7,64 a 10,18 kg MS/kg de ganho, sendo que as variedades que proporcionaram maiores ganhos de peso e melhor conversão alimentar foram as que apresentavam maiores valores de digestibilidade in vitro da MS e relação FDN/açúcares mais baixas.

Diferentes métodos podem ser usados para avaliação da diversidade nutricional de forrageiras, baseando-se em diversas variáveis discriminatórias; entre eles a análise de agrupamento, pela qual podem ser utilizadas as variáveis consideradas mais importantes para avaliação de determinada forrageira.

Diversos autores têm utilizado técnicas de análise multivariada para avaliação de forrageiras. Strapasson et al. (2000) utilizaram essa técnica para caracterizar acessos das espécies Paspalum guenoarum e Paspalum plicatulum e Azevêdo et al. (2003a), para avaliar a divergência nutricional de variedades de cana-de-açúcar. De acordo com Cruz \& Regazzi (1997), a aplicação da técnica de análise de agrupamento tem sido intensa em áreas como ciências biológicas, medicina, geologia, ciências sociais, entre outras.

O objetivo neste trabalho foi avaliar a divergência nutricional de diferentes genótipos de cana-de-açúcar, visando à produção qualitativa de forragem para bovinos. 


\section{Material e Métodos}

Foram avaliados os seguintes genótipos de cana-deaçúcar (Saccharum spp.): RB72454, RB835486, SP80-1842, IAC86-2480, RB867515, SP79-1011, SP80-1816, SP81-3250e SP91-1049, RB977512, RB935566, RB925345 eRB977625. Os quatro últimos genótipos relacionados são clones desenvolvidos pelo programa de melhoramento genético da canade-açúcar da Universidade Federal de Viçosa e os demais, variedades comerciais empregadas na produção de açúcar e de álcool no Brasil, com exceção da variedade IAC86-2480, desenvolvida exclusivamente para fins forrageiro pelo Instituto Agronômico de Campinas - IAC.

As amostras dos genótipos foram coletadas no Centro de Pesquisa e melhoramento da cana-de-açúcar (CECA) da UFV, Município de Oratório-MG, localizado a uma altitude média de $422 \mathrm{~m}$, com temperatura média anual do ar de $23,8^{\circ} \mathrm{C}$, média das máximas de $29,5^{\circ} \mathrm{C}$ e média das mínimas de $15^{\circ} \mathrm{C}$. O clima, segundo a classificação de Köppen, é do tipo Cwa, a umidade relativa média do ar, de $64,7 \%$, e a precipitação pluviométrica média anual, de 1.369,6 mm, que se caracteriza por duas estações bem definidas, sendo que $80 \%$ das chuvas ocorrem entre os meses de outubro e março (período chuvoso) e os $20 \%$ restantes, entre os meses de abril e setembro (período seco) (Coelho \& Ribeiro, 1988).

Os cortes foram realizados em maio de 2003, observando-se que o corte anterior foi realizando em junho de 2002. Foram colhidas dez amostras da planta inteira (colmo mais folhas) por clone, efetuando-se uma desfolha em cada corte para retirada das folhas secas, como é normalmente feito quando se fornece esta forrageira aos animais. Estas amostras foram desintegradas em ensiladora estacionária, para obtenção de uma amostra composta de, aproximadamente, $3 \mathrm{~kg}$, que foi devidamente empacotada em sacos plásticos e armazenada sob refrigeração $\left(-20^{\circ} \mathrm{C}\right)$ para análises posteriores.

As análises bromatológicas e o ensaio de degradabilidade in vitro foram realizados nas dependências do Laboratório de Nutrição Animal do Departamento de Zootecnia da Universidade Federal de Viçosa - MG.

Inicialmente, as amostras foram pré-secas em estufa de ventilação forçada a $60^{\circ} \mathrm{C}$, por 96 horas, para posterior moagem em peneira de $1 \mathrm{~mm}$.

As variáveis avaliadas neste estudo foram: FDN, HEM, obtida pela diferença entre FDN e FDA, LIG, utilizando-se permanganato de potássio, conforme Van Soest \& Robertson (1985); relação FDN carboidratos solúveis; fração indegradável da FDN (I); taxa de degradação da fração potencialmente degradável da $\mathrm{FDN}\left(\mathrm{kd}_{\mathrm{FDN}}\right)$; e taxa de degradação dos carboidratos totais $\left(\mathrm{kd}_{\mathrm{CT}}\right)$. A análise de carboidratos solúveis (CS) foi realizada de acordo com o método descrito por Silva \& Queiroz (2002).

A fração indegradável da FDN (I) foi obtida pela técnica gravimétrica, via incubação in vitro por 144 horas da fibra insolúvel em detergente neutro, e a fração potencialmente degradável da FDN (b'), pela fórmula b'=100 - I.

As taxas de degradação dos CT e da FDN foram estimadas pela técnica de produção de gases. Aproximadamente $100 \mathrm{mg}$ das amostras pré-secas a $60^{\circ} \mathrm{C}$ por 72 horas e $100 \mathrm{mg}$ de amostras da fibra insolúvel em detergente neutro, moídas em peneiras com crivos de $1 \mathrm{~mm}$, foram incubados em triplicata, em frascos de vidro de $50 \mathrm{~mL}$ contendo $8 \mathrm{~mL}$ da solução tampão de McDougall (McDougall, 1949), previamente reduzida com $\mathrm{CO}_{2}(\mathrm{pH}$ 6,9-7,0) e $2 \mathrm{~mL}$ de inóculo ruminal, provenientes de dois bovinos fistulados no rúmen. Imediatamente após, os frascos receberam tampa de borracha e lacre de alumínio e permaneceram em mesa de agitação orbital ( $44 \mathrm{rpm})$ em uma sala climatizada, mantida a $39^{\circ} \mathrm{C}$. As leituras de pressão foram realizadas por meio de um sensor de pressão acoplado a um voltímetro, nos seguintes tempos: $1,2,3,4,5,6,9,12,18,24,30,36,48,60,72,96$ e 120 horas (Maurício et al., 1999). As leituras realizadas em volts foram convertidas para mL, conforme Pell \& Schofield (1993). A cinética da produção cumulativa dos gases foi analisada empregando-se o modelo de regressão não-linear de Brody:

$$
V(t)=V f\left[1-b^{\left(-\mathrm{c}^{*} \mathrm{t}\right)}\right] .
$$

Nesse modelo, $V(t)$ é o volume de gases acumulado $(\mathrm{mL})$ no tempo " $t$ "; $V f$, o volume total de gases produzido em $\mathrm{t}$ $(\mathrm{mL})$; c, a taxa específica de produção de gases; b, o parâmetro de forma, sem interpretação biológica; e t, o tempo de incubação.

Após a obtenção dos resultados laboratoriais, procedeu-se à redução dos valores à média dos clones, empregando-se todas as variáveis avaliadas como base para análise multivariada de agrupamento por otimização, segundo o método de Tocher(Cruz\& Regazzi, 1997). Adotou-se a distância euclidiana média como medida básica de dissimilaridade, calculada após a padronização das informações.

Os procedimentos estatísticos foram realizados por meio do Sistema para Análises Estatísticas e Genéticas SAEG, versão 8.0 (UFV, 2000).

\section{Resultados e Discussão}

A composição bromatológica dos 13 genótipos de canade-açúcar encontra-se na Tabela 1, na qual pode ser visualizado que os teores de MS, FDN, FDA e LIG estão de acordo com a variação na composição de 15 variedades de cana-de-açúcar verificados por Azevedo et al.(2003a), de 23, 1 a 28,7\% MS, 43, 8 a $53,8 \% \mathrm{FDN}$ e 24,3 a 29,7\% FDA. 
Estes dados também estão de acordo com aqueles compilados de trabalhos publicados no Brasil (Valadares Filho et al., 2002), nos quais foram observados teores médios, com base na MS, de 55,9 \pm 8,2\% para FDN, em 39 observações; $10,0 \pm 2,8 \%$ para LIG, em 52 observações; $20,5 \pm 4,9 \%$ para HEM, em 14 observações.

O conteúdo de lignina variou de 9,97 a 13,54\% da FDN, com valor médio de $12,13 \%$, inferior aos encontrados por Fernandes et al. (2003a) e Azevêdo et al. (2003a), de 14,25 e $14,10 \%$, respectivamente, em variedades de cana-deaçúcar colhida em soca aos 14 meses. Normalmente, o teor de lignina em relação ao conteúdo de FDN da forragem está negativamente correlacionado à degradação da fração fibrosa, destacando-se que Van Soest (1981) concluiu que a lignina impede a digestão dos carboidratos da parede celular em aproximadamente 1,4 vezes o seu próprio peso.

Van Soest (1994) também considerou que o teor de FDN apresenta estreita relação com o consumo das forragens e, conseqüentemente, com o desempenho dos animais. O valor da relação $(3,0)$ entre os teores de FDN e de carboidratos solúveis (FDN/CS) tem sido utilizado na avaliação da qualidade nutritiva da canade-açúcar, sendo considerado indicativo de que a FDN não seria limitante ao consumo de MS e, conseqüentemente, de açúcares, que fornecem a maior parte da energia digestível para os animais alimentados com esta forrageira (Rodrigues et al., 2001). Os valores observados para as variedades estudadas mantiveram-se abaixo de 1,8 , com média de 1,33 .

Os resultados médios das estimativas das variáveis obtidas na cinética de degradação in vitro são apresenta- dos na Tabela 2. Os teores de fração indegradável da FDN (I) estão dentro da variação citada por Valadares Filho et al. (2002), com estimativa de 45,1 $\pm 12,7 \%$ em seis observações. Entretanto, Azevêdo et al. (2003a) e Fernandes et al. (2003a) encontraram teores da fração indegradável da FDN (I) bem superiores, variando de 52,4 a 61,7 e de 57,3 a $60,2 \%$, respectivamente.

Os teores mais elevados da fração indegradável da FDN encontrados por estes autores, provavelmente, estão relacionados ao estádio de maturidade mais avançado (14 a 18 meses de rebrotação) das variedades avaliadas, evidenciado pelos maiores teores de lignina.

As taxas de digestão da FDN ( $\left.\mathrm{kd}_{\mathrm{FDN}}\right)$ estimadas para os clones avaliados foram inferiores às observadas em trabalhos recentes, nos quais foram verificados valores de 0,0212 a 0,0310 $\mathrm{h}^{-1}$ (Campos etal., 2001; Azevêdo etal.,2003b; Fernandes et al., 2003b; Campos, 2004). As estimativas das taxas de degradação dos $\mathrm{CT}\left(\mathrm{kd}_{\mathrm{CT}}\right)$, no entanto, foram bem superiores aos valores encontrados por Campos (2004) e Azevêdo et al. (2003b), de 0,0456 e $0,0410 \mathrm{~h}^{-1}$, respectivamente.

Neste estudo, todos os genótipos de cana-de-açúcar foram cultivados no mesmo tipo de solo e sob condições agronômicas idênticas. Portanto, a variabilidade encontrada para as variáveis, entre os tratamentos, pode estar relacionada às suas características genéticas, refletidas em grande variabilidade sobre os parâmetros de degradação ruminal e a composição bromatológica.

A contribuição das variáveis para discriminação dos grupos encontra-se na Tabela 3. A primeira análise de agrupamento (Agrupamento 1) foi realizada com todas as variáveis propostas inicialmente no trabalho; contudo,

Tabela 1 - Teores médios de MS, FDN, FDA, HEM, LIG e relação FDN:carboidratos solúveis (CS) de genótipos de cana-de-açúcar Table 1 - Mean values of DM, NDF, ADF, HEM, LIG, and NDF:soluble carbohydrates (SC) ratio of sugar cane genotypes

\begin{tabular}{|c|c|c|c|c|c|c|}
\hline $\begin{array}{l}\text { Genótipo } \\
\text { Genotype }\end{array}$ & $\begin{array}{l}\mathrm{MS}(\%) \\
D M(\%)\end{array}$ & $\begin{array}{l}\text { FDN (\%MS) } \\
N D F(\% D M)\end{array}$ & $\begin{array}{c}\text { FDA }(\% \mathrm{MS}) \\
A D F(\% D M)\end{array}$ & $\begin{array}{c}\text { Hem }(\% \mathrm{MS}) \\
\text { Hem }(\% D M)\end{array}$ & $\begin{array}{c}\operatorname{Lig}(\% \mathrm{FDN}) \\
\operatorname{Lig}(\% N D F)\end{array}$ & $\begin{array}{c}\mathrm{FDN} / \mathrm{CS} \\
N D F / S C\end{array}$ \\
\hline & & & & & & \\
\hline RB /2454 & 23,42 & 55,46 & 32,24 & 23,22 & 11,68 & 1,37 \\
\hline RB835486 & 20,80 & 53,53 & 30,18 & 23,35 & 10,63 & 1,19 \\
\hline SP80-1842 & 26,48 & 55,66 & 34,63 & 21,03 & 12,45 & 1,28 \\
\hline IAC $86-2480$ & 20,14 & 57,06 & 34,54 & 22,52 & 11,11 & 1,41 \\
\hline RB977512 & 24,66 & 50,65 & 30,41 & 20,24 & 13,26 & 1,20 \\
\hline RB867515 & 25,40 & 55,64 & 33,47 & 22,17 & 9,97 & 1,32 \\
\hline RB935566 & 20,80 & 57,82 & 35,39 & 22,43 & 12,48 & 1,72 \\
\hline RB925345 & 27,60 & 58,51 & 35,99 & 22,51 & 13,54 & 1,49 \\
\hline RB977625 & 25,00 & 55,17 & 33,00 & 22,17 & 12,55 & 1,34 \\
\hline SP79-1011 & 26,38 & 53,45 & 31,84 & 21,61 & 11,69 & 1,21 \\
\hline SP80-1816 & 26,19 & 53,45 & 32,03 & 21,42 & 12,64 & 1,26 \\
\hline SP81-3250 & 24,86 & 52,52 & 30,44 & 22,08 & 12,59 & 1,23 \\
\hline SP91-1049 & 25,44 & 54,74 & 33,00 & 21,74 & 13,09 & 1,37 \\
\hline Média & 24,40 & 54,90 & 32,86 & 22,04 & 12,13 & 1,33 \\
\hline \multicolumn{7}{|l|}{$\begin{array}{l}\text { Mean } \\
\text { EP }^{1}\end{array}$} \\
\hline$S E^{l}$ & 2,41 & 2,19 & 1,91 & 0,85 & 1,06 & 0,14 \\
\hline
\end{tabular}

${ }^{1} \mathrm{EP}=$ erro-padrão $(S E=$ standard error). 
Tabela 2 - Média das estimativas para as variáveis degradação potencial da fração da FDN (b'), fração indegradável da FDN (I), taxa de degradação dos carboidratos totais $\left(\mathrm{kd}_{\mathrm{CT}}\right)$ e taxa de degradação da FDN $\left(\mathrm{kd}_{\mathrm{FDN}}\right)$ de genótipos de cana de açúcar

Table 2 - Mean estimates of the variables potential degradation of the NDF fraction ( $\left.b^{\prime}\right)$, NDF undegradable fraction (I), total carbohydrate degradation rate $\left(k d_{T C}\right)$, and NDF degradation rate $\left(k d_{N D F}\right)$ of sugarcane genotypes

\begin{tabular}{|c|c|c|c|c|}
\hline \multirow[t]{2}{*}{$\begin{array}{l}\text { Genótipo } \\
\text { Genotype }\end{array}$} & \multicolumn{4}{|c|}{$\begin{array}{l}\text { Variável } \\
\text { Variable }\end{array}$} \\
\hline & $b^{\prime}(\%)$ & I (\%) & $\begin{array}{c}\mathrm{kd}_{\mathrm{CT}}\left(\mathrm{h}^{-1}\right) \\
k d_{T C}\left(h^{-1}\right)\end{array}$ & $\begin{array}{c}\mathrm{kd}_{\mathrm{FDN}}\left(\mathrm{h}^{-1}\right) \\
k d_{N D F}\left(h^{-1}\right)\end{array}$ \\
\hline RB72454 & 64,18 & 35,82 & 0,0625 & 0,0173 \\
\hline RB835486 & 65,23 & 34,77 & 0,0757 & 0,0165 \\
\hline SP80-1842 & 58,05 & 41,95 & 0,0691 & 0,0116 \\
\hline RB867515 & 56,87 & 43,13 & 0,0649 & 0,0144 \\
\hline RB935566 & 60,15 & 39,85 & 0,0399 & 0,0163 \\
\hline RB925345 & 58,93 & 41,07 & 0,0470 & 0,0124 \\
\hline RB977625 & 59,16 & 40,84 & 0,0694 & 0,0101 \\
\hline SP79-1011 & 62,15 & 37,85 & 0,0774 & 0,0145 \\
\hline SP80-1816 & 62,16 & 37,84 & 0,0816 & 0,0130 \\
\hline
\end{tabular}

${ }^{1} \mathrm{EP}=$ erro-padrão $(S E$ = standard error $)$.

para permanência de uma variável no modelo, adotou-se o limite mínimo de $10 \%$ de contribuição da variável para o poder total de discriminação entre grupos. Assim, foi realizada uma segunda análise (Agrupamento 2) com a exclusão das variáveis FDN/CS e lignina, que contribuíram com apenas 6,41 e 8,97\% (Tabela 3), respectivamente. Esse comportamento parece ser reflexo da maior estabilidade destas variáveis com relação à variação entre clones, dificultando sua contribuição na avaliação de divergências nutricionais entre os genótipos.

É interessante observar que, com o descarte das duas variáveis do Agrupamento 1, o aumento na contribuição das variáveis $\mathrm{FDN}$ e taxa de degradação da $\mathrm{MS}\left(\mathrm{kd}_{\mathrm{CT}}\right)$ foram da mesma magnitude, de modo que estas variáveis passaram a apresentar a maior contribuição para discriminação dos grupos, com um valor de 25,64\% (Tabela 3).

A fração indegradável da FDN (I) e a taxa de degradação da FDN $\left(\mathrm{kd}_{\mathrm{FDN}}\right)$ sofreram pequeno aumento, passando de 10,26 para $11,54 \%$ e de 15,38 para $16,67 \%$, respectivamente, enquanto a variável hemicelulose (Hem) não sofreu alteração (Tabela 3).

Na segunda análise (Agrupamento 2), a variável que apresentou a menor contribuição foi a fração indegradável da fibra em detergente neutro (I), contribuindo com 11,54\% (Tabela 3), valor superior ao limite de $10 \%$. Azevêdo et al. (2003a), utilizando a análise de componentes principais, observaram que a fração indegradável da FDN (I) foi a variável de menor importância para explicar a variabilidade nutricional dos genótipos de cana-de-açúcar estudados. No entanto, estes autores, também obtiveram menor impor- tância para variável FDN na avaliação da divergência nutricional, a qual não foi descartada, pois foi necessária para obtenção de outras variáveis utilizadas no estudo.

No método de Tocher, adota-se como critério que a média das medidas de dissimilaridade dentro de cada grupo deve ser menor que as distâncias entre quaisquer grupos (Cruz \& Regazzi, 1997). A maior distância encontrada entre as menores em relação a cada um dos clones foi de 1,7196. Assim, foi estabelecido $\mathrm{q}=1,7196$ como o limite de acréscimo, na média da distância intragrupo, para a formação ou inclusão de novo genótipo no grupo.

A aplicação de agrupamento por otimização de Tocher utilizando a matriz de distâncias euclidiana média permitiu

Tabela 3 - Contribuição das variáveis para discriminação dos grupos

Table 3 - Variables contribution for group discrimination

\begin{tabular}{lcc}
\hline $\begin{array}{l}\text { Variável } \\
\text { Variable }\end{array}$ & \multicolumn{2}{c}{$\begin{array}{c}\text { Contribuição das variáveis (\%) } \\
\text { Variables contribution (\%) }\end{array}$} \\
\cline { 2 - 3 } & $\begin{array}{c}\text { Agrupamento } \\
\text { Cluster 1 }\end{array}$ & $\begin{array}{c}\text { Agrupamento } 2 \\
\text { Cluster 2 }\end{array}$ \\
\hline FDN & 19,23 & 25,64 \\
$N D F$ & 10,26 & 11,54 \\
$\mathrm{I}$ & 20,51 & 20,51 \\
$\mathrm{Hem}$ & 6,41 & - \\
$\mathrm{FDN} / \mathrm{CS}$ & & - \\
$N D F / S C$ & 8,97 & 25,64 \\
$\mathrm{Lig}$ & 19,23 & 16,67 \\
$\mathrm{kd}_{\mathrm{CT}}$ & 15,38 & \\
$k d_{T C}$ & & \\
$\mathrm{kd}_{\mathrm{FDN}}$ & & \\
$k d_{N D F}$ & &
\end{tabular}


o estabelecimento de três grupos (Tabela 4). Na Tabela 4, constam também as médias das variáveis dentro de cada grupo e as distâncias médias intragrupo.

O grupo I foi constituído somente pelo clone RB977512, considerado o de melhor qualidade nutricional, por apresentar os menores teores de FDN (50,65\%) e de fração indegradável da FDN (I) $(35,42 \%)$ e a maior taxa de degradação dos carboidratos totais $\left(\mathrm{kd}_{\mathrm{CT}}\right)$. Contudo, este clone apresentou taxa de degradação da FDN $\left(\mathrm{kd}_{\mathrm{FDN}}\right)\left(0,0125 \mathrm{~h}^{-1}\right)$ menor que a média dos demais grupos. Entretanto, mesmo com menor taxa de degradação da FDN, este aspecto não se torna tão negativo, pois sua contribuição para discriminação foi bem inferior à da FDN, da hemicelulose e dos carboidratos totais (Tabela 3 ).

A avaliação do conteúdo de FDN e de sua fração indegradável (I) das variedades de cana-de-açúcar são de grande importância, em razão de sua influência no consumo de alimentos. O aumento no teor de FDN resulta em ampliação proporcional no consumo de FDN por quilo de matéria seca, o que ocasiona aumento proporcional na competição por escape das partículas da massa de alimento no rúmen (Ellis et al., 2000). Esse aumento na competição por escape resulta em aumento no tempo de retenção, que, por sua vez, reflete negativamente na regulação física do enchimento ruminal, promovendo a redução do consumo de alimentos pelo animal.

Tabela 4 - Grupos de genótipos de cana-de-açúcar e média das variáveis em cada grupo

Table 4 - Groups of sugarcane genotypes, and mean of the variables within each group

\begin{tabular}{lccc}
\hline Itens & \multicolumn{3}{c}{$\begin{array}{c}\text { Grupo } \\
\text { Group }\end{array}$} \\
\cline { 2 - 4 } & I & II & III \\
\hline
\end{tabular}

Genótipos

Genotypes
RB935566 RB925345 IAC $86-2480$ SP80-1816

RB977512 RB977625 SP $80-1842$ RB 867515 SP91-1049

\begin{tabular}{|c|c|c|c|}
\hline $\begin{array}{l}\text { Distância média } \\
\text { intragrupo } \\
\text { Mean distance withir }\end{array}$ & - & 1,5327 & 1,6925 \\
\hline $\begin{array}{l}\text { FDN (\%MS) } \\
N D F(\% D M)\end{array}$ & 50,65 & 56,37 & 53,68 \\
\hline $\begin{array}{l}\text { I (\%MS) } \\
\text { I (\%DM) }\end{array}$ & 35,42 & 41,39 & 36,90 \\
\hline $\begin{array}{l}\text { Hem }(\% \mathrm{MS}) \\
\text { Hem }(\% D M)\end{array}$ & 20,24 & 22,08 & 22,33 \\
\hline $\begin{array}{l}\mathrm{kd}_{\mathrm{CT}}\left(\mathrm{h}^{-1}\right) \\
k d_{T C}\left(h^{-1}\right)\end{array}$ & 0,0963 & 0,0645 & 0,0782 \\
\hline $\begin{array}{l}\mathrm{kd}_{\mathrm{FDN}}\left(\mathrm{h}^{-1}\right) \\
k d_{N D F}\left(h^{-1}\right)\end{array}$ & 0,0125 & 0,0136 & 0,0155 \\
\hline
\end{tabular}

A menor taxa de degradação da FDN estimada para o clone RB977512 provavelmente está relacionada à maior concentração de lignina $(13,26 \%$ FDN) (Tabela 1) encontrada para este clone. Os ácidos fenólicos de lignina "noncore" esterificados somente aos polissacarídeos, sem ligação com o polímero de lignina "core", diminuem a taxa de degradação da parede celular, mas não alteram a extensão da degradação, pois as ligações éster são susceptíveis à quebra enzimática (Jung \& Deetz, 1993), o que justifica o fato, embora o clone RB977512 apresente baixa taxa de degradação da FDN e menor teor da fração indegradável da FDN em relação aos outros grupos.

No grupo II (Tabela 4) são apresentados os clones considerados de menor interesse para a produção de forragem para ruminantes nas condições avaliadas neste trabalho. Este grupo apresentou a maior média para os teores de FDN $(56,37 \%)$ e a fração indegradável da FDN (I) $(41,39 \%)$ e a menor taxa de degradação dos carboidratos totais $\left(0,0645 \mathrm{~h}^{-1}\right)$.

O grupo III é composto pelas variedades SP79-1011, SP80-1816, SP81-3250, RB835486 e RB72454, sendo que as variedades "SP" mostraram-se altamente similares, como confirmado pelos resultados expressos nas Tabelas 1 e 2 . Neste grupo estão as variedades SP79-1011 e SP80-1816, que apresentaram a menor distância euclidiana média $(0,2178)$ e, portanto, as mais próximas.

É interessante ressaltar que as variedades que compõem o grupo III estão entre as dez mais cultivadas no Brasil. Considerando sua grande disponibilidade e avaliando as médias das variáveis apresentadas, a variedade RB835486 também pode ser considerada de grande valor para a finalidade forrageira. Esta variedade apresentou teor de FDN de 53,53\%, taxa de degradação dos carboidratos totais $\left(\mathrm{kd}_{\mathrm{CT}}\right)$ de 0,0757 e fração indegradável da FDN (I) de 34,77 , teor de lignina (\%FDN) $24,7 \%$ menor e taxa de degradação da FDN $\left(\mathrm{kd}_{\mathrm{FDN}}\right) 32 \%$ superior ao clone RB977512.

A maior taxa de degradação da FDN pode ser bastante favorável, pois aumenta a possibilidade de escape da fração não-digerida. As taxas de passagem e de degradação afetam o consumo, de modo que altas taxas de degradação implicam resíduo ruminal mínimo e rápida remoção (Paterson et al., 1994).

O fato de o clone RB977512 e a variedade RB835486 apresentarem valores de lignina diferentes (13,26 e 10,63\% da FDN, respectivamente) e teores da fração indegradável muito próximos talvez possa ser explicado pelos modelos conceituais desenvolvidos independentemente por Chesson (1993) e Jung \& Deetz (1993) para descrever como 
a lignificação da parede celular impede a degradação dos polissacarídeos pelos microrganismos ruminais. Os dois modelos sugerem que nem todas as "ligninas" afetam a degradação da parede celular da mesma forma. Nesses modelos, a influência da lignina seria modulada por sua composição e estrutura e pelos ácidos fenólicos da parede celular (Jung \& Allen, 1995).

De acordo com Jung \& Allen (1995), os ésteres de ácidos fenólicos são extensamente rompidos no processo de fermentação ruminal e, portanto, a redução na digestibilidade causada por esses ésteres deve estar mais relacionada à redução da taxa de degradação dos polissacarídeos que de sua extensão, sugerindo que a menor taxa de degradação da FDN observada para o clone RB977512, em relação à variedade RB835486, pode ser conseqüência da maior concentração de ésteres de ácidos fenólicos na parede celular.

De acordo com Wilson \& Mertens (1995), a estrutura física dos tecidos com parede celular espessa e o arranjo das células nos tecidos podem limitar a digestão da parede até mais que a composição química da parede celular.

Nos dados apresentados por Rodrigues et al. (2001), que avaliaram a qualidade de 18 variedades de cana-deaçúcar, também pode ser observada a melhor qualidade da variedade RB835486 sobre as demais, apresentando o menor teor de FDN $(45,6 \%)$ e os maiores teores de digestibilidade in vitro da MS (DIVMS) nas duas épocas avaliadas (67,4 e 68,9\%). Rodrigues et al. (2002) estudaram o valor nutritivo de quatro variedades de cana-de-açúcar e também observaram superioridade para a variedade RB835486, permitindo a obtenção de maiores ganhos de peso por novilhas em crescimento.

\section{Conclusões}

As variáveis FDN, fração indegradável da FDN, hemicelulose, taxa de degradação dos CT e taxa de degradação da FDN mostraram-se eficazes para avaliação da divergência nutricional da cana-de-açúcar. Entre os genótipos estudados, o clone RB977512 pode ser considerado o de melhor qualidade nutricional.

\section{Literatura Citada}

ANDERSON, B.; WARD, J.K.; VOGEL, K.P. et al. Forage quality and performance of yearlings grazing switchgrass strains selected for differing digestibility. Journal of Animal Science, v.66, p.2239-2244, 1988.

AZEVÊDO, J.A.G.; PEREIRA, J.C.; CARNEIRO, P.C.S. et al. Avaliação da divergência nutricional de variedades de cana-deaçúcar (Saccharum spp.). Revista Brasileira de Zootecnia, v.32, n.6, p.1431-1442, 2003a.
AZEVÊDO, J.A.G.; PEREIRA, J.C.; QUEIROZ, A.C. et al. Composição químico-bromatológica, fracionamento de carboidratos e cinética da degradação in vitro da fibra de três variedades de cana-de-açúcar (Saccharum spp.). Revista Brasileira de Zootecnia, v.32, n.6, p.1443-1453, 2003b.

BARBOSA, M.H.P. Perspectivas para o melhoramento da cana-deaçúcar. In: SIMPÓSIO DE ATUALIZAÇÃO EM GENÉTICA E MELHORAMENTO DE PLANTAS. GENÉTICA E MELHORAMENTO DE ESPÉCIES DE PROPAGAÇÃO VEGETATIVA, 4., 2000, Lavras. Anais... Lavras: Universidade Federal de Lavras, 2000. p.1-17.

CAMPOS, P.R.S.C. Estimativa do valor energético e da taxa de degradação da fibra em detergente neutro de alguns volumosos em ovinos. Viçosa, MG: Universidade Federal de Viçosa, 2004. 56p. Dissertação (Mestrado em Zootecnia) Universidade Federal de Viçosa, 2004.

CAMPOS, F.P.; SAMPAIO, A.A.M.; VIEIRA, P.F. et al. Digestibilidade in vitro/gás de volumosos exclusivos ou combinados avaliados pelo resíduo remanescente da digestão da matéria seca e produção de gás. Revista Brasileira de Zootecnia, v.30, n.5, p.1579-1589, 2001.

CHESSON, A. Mechanistic models of forage cell wall degradation. In: JUNG, H.G.; BUXTON, D.R.; HATFIELD, R.D. et al. (Eds.) Forage cell wall structure and digestibility. Madison: 1993. p. 347-376.

COELHO, M.B.; RIBEIRO, S.N.N. Análise dos dados meteorológicos do Município de Ponte Nova - MG. Brasil Açucareiro, v.106, n.4, p.26-36, 1988

COLLINS, M.; CASLER, M.D. Forage quality of five cool-season grasses. I. Cultivar effects. Animal Feed Science and Technology, v.72, n.1, p.197-207, 1990a.

COLLINS, M.; CASLER, M.D. Forage quality of five cool-season grasses. II. Species effects. Animal Feed Science and Technology, v.27, n.1, p.209-218, 1990b.

CRUZ, C.D.; REGAZZI, A.J. Modelos biométricos aplicados ao melhoramento genético. 2.ed. Viçosa, MG: Universidade Federal de Viçosa, 1997. 390p.

DIETZ, G.; LUCCI, C.S.; MELOTTI, L. Degradabilidade ruminal da fibra da cana-de-açúcar, pela técnica dos sacos de náilon in situ, quando suplementada por várias fontes protéicas. Brazilian Journal Veterinary Research and Animal Science, v.34, n.6, p.352-357, 1997.

ELLIS, W.C.; POPPI, D.; MATIS, J.H. Feed intake in ruminants: kinetic aspects. In: D'MELLO, J.P.F. (Ed.) Farm animal metabolism and nutrition. Edinburgh: 2000. p.335-364.

FERNANDES, A.M.; QUEIROZ, A.C.; PEREIRA, J.C. et al. Composição químico-bromatológica de cana-de-açúcar (Saccharum spp L.) com diferentes ciclos de produção (precoce e intermediário) em três idades de corte. Revista Brasileira de Zootecnia, v.32, n.4, p.977-985, 2003a.

FERNANDES, A.M.; QUEIROZ, A.C.; PEREIRA, J.C. et al. Fracionamento e cinética da degradação in vitro dos carboidratos constituintes da cana-de-açúcar com diferentes ciclos de produção em três idades de corte. Revista Brasileira de Zootecnia, v.32, n.6, p.1778-1785, 2003b (supl. 1).

GOODING, E.G.B. Effect of quality of cane on its value as livestock feed. Tropical Animal Production, v.7, n.1, p.72-91, 1982.

HALL, J.W.; MAJAK, W.; STOUT, D.G. et al. Bloat in cattle fed alfalfa selected for low initial rate of digestion. Canadian Journal of Animal Science, v.74, p.451-456, 1994.

JUNG, H.G.; ALLEN, M.S. Characteristics of plant cell wall affecting intake and digestibility forages by ruminants. Journal of Animal Science, v.73, p.2774-2790, 1995.

JUNG, H.G.; DEETZ, D.A. Cell wall lignification and degradability. In: JUNG, H.G.; BUXTON, D.R.; HATFIELD, R.D. (Eds.) Forage cell wall structure and digestibility. Madison: 1993. p.315-346.

LANDELL, M.G.A.; CAMPANA, M.P.; RODRIGUES, A.A. et al. A variedade IAC86-2480 como nova opção de cana-de-açúcar 
para fins forrageiros: manejo de produção de uso na alimentação animal. Campinas: Instituto Agronômico, 2002. 39p. (Série Tecnologia APTA, boletim técnico IAC; 193).

MAURÍCIO, R.M.; MOULD, F.L.; DHANOA, M.S. et al. A semiautomated in vitro gas production technique for ruminant feedstuff evaluation. Animal Feed Science and Technology, v.79, p.321-330, 1999.

McDOUGAL, E.I. Studies on ruminal saliva. 1. The composition and output of sheep's saliva. Biochemical Journal, v.43, n.1, p.99-109, 1949.

PATERSON, J.A.; BELYEA, R.L.; BOWMAN, J.P. et al. The impact of forage quality and supplementation regimen on ruminant animal intake and performance. In: FAHEY JR., G.C. (Ed.). Forage quality, evaluation and utilization. Madison: American Society of Agronomy, 1994. p.59-114.

PELL, A.N.; SCHOFIELD, P. Computerized monitoring of gas production to measure forage digestion in vitro. Journal of Dairy Science, v.76, n.9, p.1063-1073, 1993.

POPPI, D.P.; HENDRICKSON, R.E.; MINSON, D.J. The relative resistance to escape of leaf and stem particles from the rumen of cattle. Journal of Agricultural Science, v.105, p.9-14, 1985.

RODRIGUES, A.A.; CRUZ, G.M.; BATISTA, L.A.R. et al. Qualidade de dezoito variedades de cana-de-açúcar como alimento para bovinos. In: REUNIÃO ANUAL DA SOCIEDADE BRASILEIRA DE ZOOTECnIA, 38., 2001, Piracicaba. Anais... São Paulo: Sociedade Brasileira de Zootecnia, 2001. CD-ROM

RODRIGUES, A.A.; CRUZ, G.M; BATISTA, L.A.R. et al. Efeito da qualidade de quatro variedades de cana-de-açúcar no ganho de peso de novilhas canchim. In: REUNIÃO ANUAL DA SOCIEDADE BRASILEIRA DE ZOOTECNIA, 39., 2002, Recife. Anais... Recife: Sociedade Brasileira de Zootecnia, 2002. CD-ROM.
SILVA, D.J.; QUEIROZ, A.C. Análise de alimentos: métodos químicos e biológicos. Viçosa, MG: Universidade Federal de Viçosa, 2002. 165p.

STRAPASSON, E.; VENCOVSKY, R.; BATISTA, L.A.R. Seleção de descritores na caracterização de germoplasma de Paspalum $s p$. Por meio de componentes principais. Revista Brasileira de Zootecnia, v.29, n.2, p.373-381, 2000.

UNIVERSIDADE FEDERAL DE VIÇOSA - UFV. SAEG - Sistema de análise estatística e genética. Versão 8.0. Viçosa, MG 2000 .

VALADARES FILHO, S.C.; ROCHA Jr., V.R; CAPPELE, E.R. Tabelas brasileiras de composição de alimentos para bovinos. Viçosa, MG: Universidade Federal de Viçosa, 2002. 297p.

Van SOEST, P.J. Nutritional ecology of the ruminant. 2.ed. New York: Cornell University Press, 1994. 476p.

Van SOEST, P.J. Limiting factors in plant residues of low digestibility. Agriculture Environment, v.6, p.135-143, 1981

Van SOEST, P.J.; ROBERTSON, J.B. Analysis of forages and fibrous foods. Ithaca: Cornell University, 1985 (Lab Manual for Animal Science, 613). 202p.

WILSON, J.R.; MERTENS, D.R. Cell wall accessibility and cell structure limitations to microbial digestion of forage. Crop Science, v.35, n.1, p.251-259, 1995. 